\title{
Forensic Discrimination Potential of Video Spectral Comparator and Micro Spectrophotometer in Analyzing Question Document and Fraud Cases in India
}

Khairkar SR*, Gaikawad SV, Kokare RN and Daundkar BB

Forensic Science Laboratories, Mumbai, India

*Corresponding author: Khairkar SR, Director of Forensic Science Laboratories, Mumbai 400098, India, Tel: +917212541424; E-mail: shyamkhairkar@gmail.com

Received Date: May 30, 2016; Accepted Date: June 21, 2016; Published Date: June 27, 2016

Copyright: (C) 2016 Khairkar SR, et al. This is an open-access article distributed under the terms of the Creative Commons Attribution License, which permits unrestricted use, distribution, and reproduction in any medium, provided the original author and source are credited.

\begin{abstract}
The aim of the study was to evaluate the discriminating power of non-destructive methods, including optical methods likes the Video spectral comparator method (VSC) and Micro spectrophotometer (MSP) used to differentiate ballpoint pen ink which is commonly used in question document and fraud cases in India. Documents have been investigated to determine the feasibility of utilizing the Video spectral comparator method (VSC) and Micro spectrophotometer (MSP) for the differentiation and comparison of inks on paper. The work focused on how to develop the most effective procedure to ensure quality, when Micro spectrophotometer is used to differentiate writing materials by characteristics color scan of each ink. Six different commercially available blue ballpoint pen inks produced from most popular pens in Indian Market which were used as research material. We have studied most selling pens in Indian market (Reynolds, Parker, and Lexis 2 types, Cello griper and local made pen) for overwriting, alternation and modification of ballpoint pen ink on documents. These pens are generally used on questioned document in forensic discrimination cases and these questioned documents cases received by forensic science laboratories regularly. In forensic discrimination cases generally initial writing is overwritten by using other ink and to identify which ink was used to overwrite is challenging task in field of forensic science. The present study highlighted that the Video Spectral Comparator method (VSC) and Micro spectrophotometer (MSP) can be used routinely in such types of document cases and it has demonstrated to be an excellent analytical method for the forensic analysis of inks on a questioned document.
\end{abstract}

Keywords: Question document; Video spectral comparator; Micro spectrophotometer; Overwriting of inks

\section{Introduction}

Forensic document examiner often deals with questions of document authenticity. To determine whether the document is genuine, a scientist may attempt to confirm who create the document, identify the material, ink used in its preparation and uncover modification to the original text. Here in forensic laboratory in India, scientist regularly receive many types of document forgery cases such as cheque, power of attorney, testaments, property papers, schoolcollege registers, medical bills, cast certificates, pan card, voting I-card, ration card for forensic examination [1]. In these types of document some documents have font and letter difference, some have ink difference in name, overwriting in letters, date and name. Some documents bearing rubber stamp impression, embossed seal, water mark, mechanically printed marks and forensic scientist should answer all questions related to these documents. In the routine work of the expert dealing with the evaluation of documents, analysis of covering materials, such as ballpoint pen inks, gels are the most frequently undertaken activity. Apart from having a good working knowledge of each of the research methods, the expert should be aware of their potential and of principles relating to the interpretation of difficult cases that do not yield an unambiguous solution. Furthermore, the development of increasingly close links between forensic laboratories has necessitated, on the one hand, establishment of common standards of research, and on the other, the widespread introduction of quality ensuring procedures in order to obtain full repeatability and reliability in conducted research. The present work concerns research into the possibility of differentiating between blue ballpoint pen inks by means of five techniques which do not require the destruction of the document, based on the following: measurement of the level of absorption and luminescence of ballpoint pen inks in visible, Infrared light and Raman absorption spectrometry [2-4]; and one technique which destroys the document - thin layer chromatography [5]. The discriminative powers of the particular methods were compared in the course of analyzing blue ballpoint pen inks produced by four popular firms that guarantee good quality and uniformity of their products. In the literature of the subject a small number of reviews have been found concerning this issue. Only a comprehensive study of the problem will be of use to experts dealing with the examination of writing materials, since in the course of their differentiation, several examination methods should be applied. The research also encompassed development of a quality ensuring procedure for the application of thin layer chromatography to the differentiation of writing materials. Forensic document examiner can use thin layer chromatographic technique or HPLC which is alternative to the TLC but this technique are consider as a destructive technique because they require removal of sample of ink from questioned document, since such document have legal importance it cannot be disturb [6,7]. Alteration, obliteration, erasure marks are not visible to human eye can often be detected through use of microscope and other non-destructive imaging device that utilize UV and IR wavelength of light. Using radiation filter at various wavelengths an imaging instrument video spectral comparator can reveal writing that has been added with different ink [8]. Ink analysis is important part of the investigation of questioned document. Although all blue or black ink may look the same, there can be some important difference in their chemical composition [9]. Analysis of document under microscope can be informative as a first step. Here, 
Page 2 of 4

we throw a light on two non-destructive techniques which is used in forensic science laboratory especially for ink comparison. Another non-destructive ink analysis technique is micro-spectrometry. This involves scanning the ink with UV or IR light to record its spectrum that is wavelength of light it absorb. Each ink should give a distinct pattern or spectrum on exposure to light. MSP is a way of discovering the true Chromaticity value which characteristics value each of ink. The spectrum of ink is therefore being compared with the standard ink [10].

\section{Material and Method}

The research material comprised 6 various blue ballpoint pen inks made by four firms: Reynolds, Parker, Lexis (2 types), Cello gripper and a local made pen.

The research had to be conducted in a specific sequence, due to the applied research methods and stimulation study. It was commenced with the most commonly applied optical and spectrometry methods. The absorption and luminescence properties in visible and infrared light of blue ballpoint pen inks were examined by means of VSC 5000 HR produced by Foster+Freeman Ltd., equipped with a system of filters letting through light of a specified wavelength - from $600 \mathrm{~nm}$ to $1000 \mathrm{~nm}$. Examinations by means of absorption spectrometry in visible and infra-red light were also carried out by means of VSC 5000 $\mathrm{HR}$, using a built-in spectrometer. All the measurements were taken in relation to a "white standard sample", which reflects in full electromagnetic radiation of length of $400 \mathrm{~nm}$ to $1100 \mathrm{~nm}$. In the course of measurement, a comparison between the amount of light absorbed by the inks on paper and the absorption of light by the standard object is made. Ten absorption measurements for each ink were made, and then the obtained spectra were averaged and arranged in pairs in order to compare them.

\section{Result and Discussion}

Here we discuss some document forgery cases in which accused person did correction or overwriting in digits such as

$$
\begin{aligned}
& \text { 1) } 1 \rightarrow 9 \\
& \text { 2) } 0 \rightarrow 6 \\
& \text { 3) } 3 \rightarrow 8
\end{aligned}
$$

To solve such types of cases we use VSC-5000 instrument and micro spectrophotometer. In Figure 1 under visible light digit 9 is seen and person used a different ball pen to make overwriting or correction then under IR light; we can distinguished two ball pen (Figure 2). Also by using micro spectrometer, we can prove which ink is overwrite on other. In Figure 3, we have a MSP spectra of digit 9 of three different points, one point is selected from a straight line of digit 9 , second point is selected from round part of digit 9 and third point is point of intersection where two ink overlaps. By comparing these three spectra we came to conclusion that overlapping spectra is similar to that ink which is used to make correction. From this data scientist can prove that overwriting is happened over there in digit and original digit can be identified. For this comparison we use 6 different types of pens (Exhibits 1-6).

\begin{tabular}{|l|l|l|}
\hline Exhibit No. & Exhibit Description & Simulation Study \\
\hline 1 & Reynold & Reynold Pen ink use to write $1 \rightarrow$ Parker Pen ink use to make it 9 \\
\hline 2 & Parker & Lexis (1 type) Pen ink use to write 0 $\rightarrow$ Parker Pen ink use to make it 6 \\
\hline 3 & Lexis (1 type) & \\
\hline 4 & Cello griper & Cello griper Pen ink use to write 0 $\rightarrow$ Local market pen ink use to make it 6 \\
\hline 5 & Local market pen & \\
\hline 6 & &
\end{tabular}

Table 1: Exhibit Description and Simulation Study.

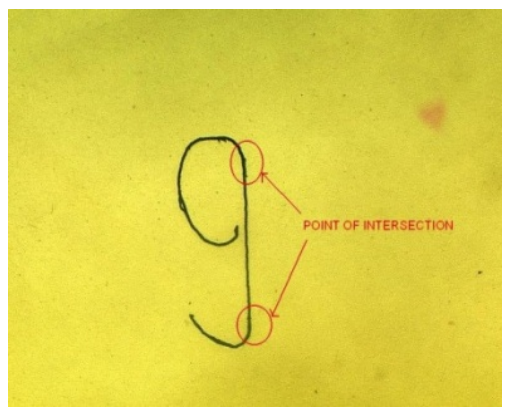

Figure 1: Two different ball pen ink exhibit-1 and exhibit-2, under VSC-5000 light $=100 \%$, long pass $=$ visible.

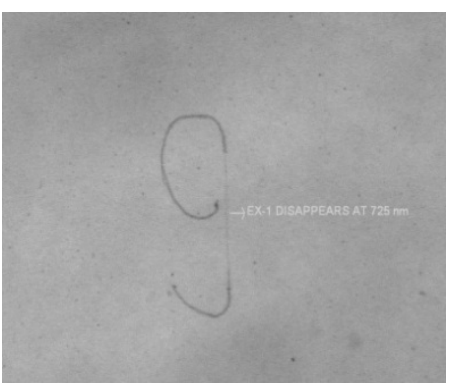

Figure 2: Showing point of intersection Ink of exhibit 1 shows absorption at $725 \mathrm{~nm}$ however ink of exhibit 2 does not show any absorption up to $778 \mathrm{~nm}$. 
Citation: Khairkar SR, Gaikawad SV, Kokare RN, Daundkar BB (2016) Forensic Discrimination Potential of Video Spectral Comparator and Micro

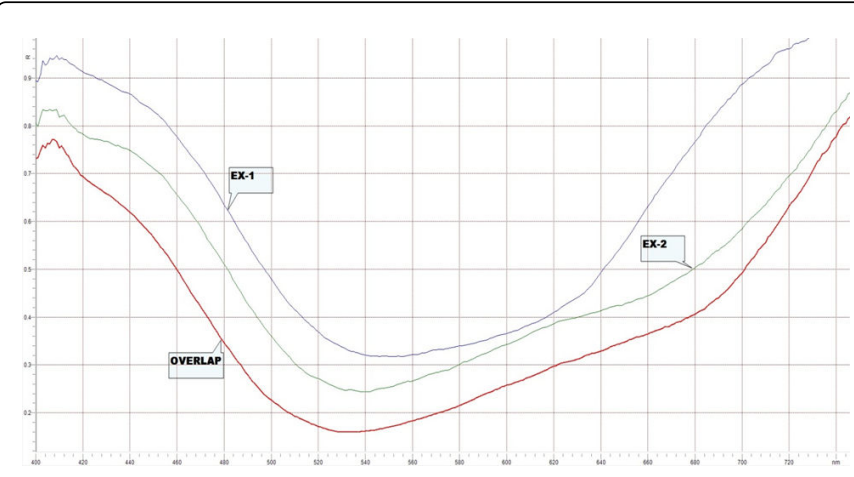

Figure 3: Graph of reflectance vs. wavelength in which overlap (point of intersection) portion graph of digit 9 is similar to graph of exhibit 2.

Similarly in image 4 two different ball pen ink are used to make overwriting of digit 0 to 6 and 3 to 8 by using same technique forensic scientist can throw light on overwriting or correction of digits and letters to identify original one (Figures 4-9).

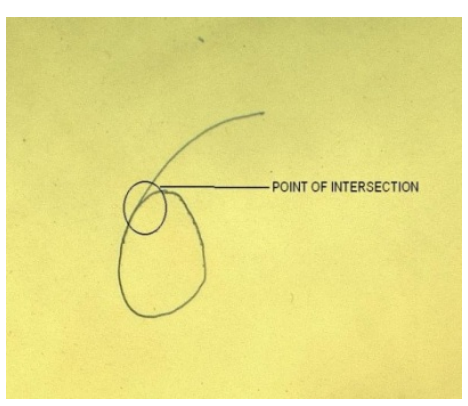

Figure 4: Showing point of intersection of two different ball pen inkexhibit-3 and exhibit-4, under VSC-5000 light $=100 \%$, long pass=visible

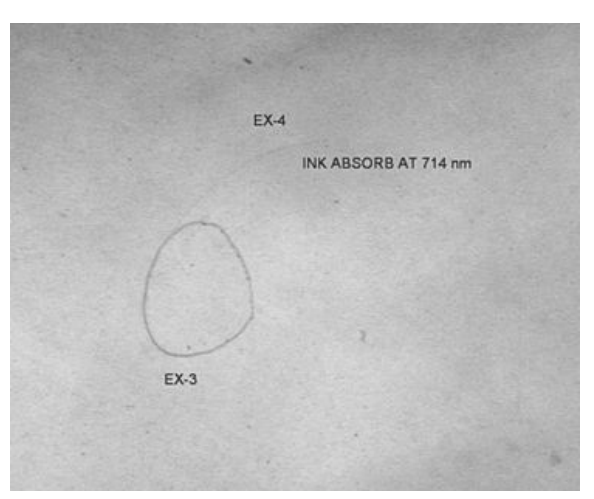

Figure 5: Ink of exhibit 4 shows absorption at $714 \mathrm{~nm}$ however ink of exhibit 3 does not show any absorption up to $778 \mathrm{~nm}$.

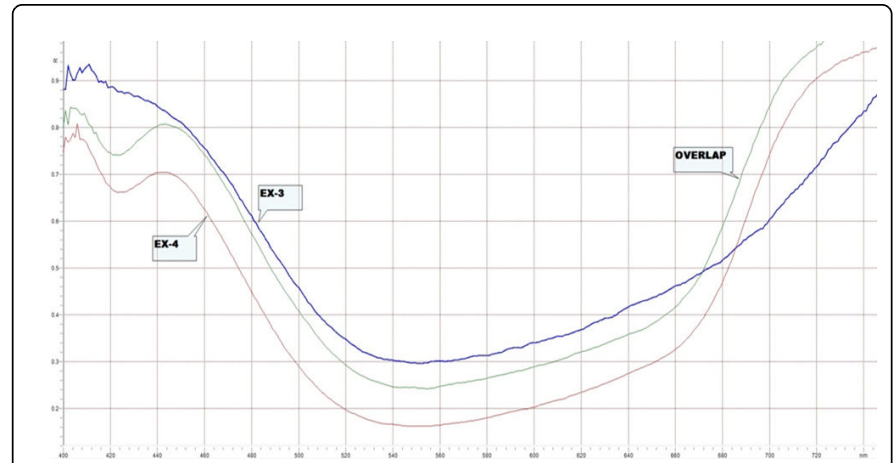

Figure 6: Graph of reflectance vs. wavelength in which overlap (point of intersection) portion graph of digit 6 is similar to graph of exhibit 4.

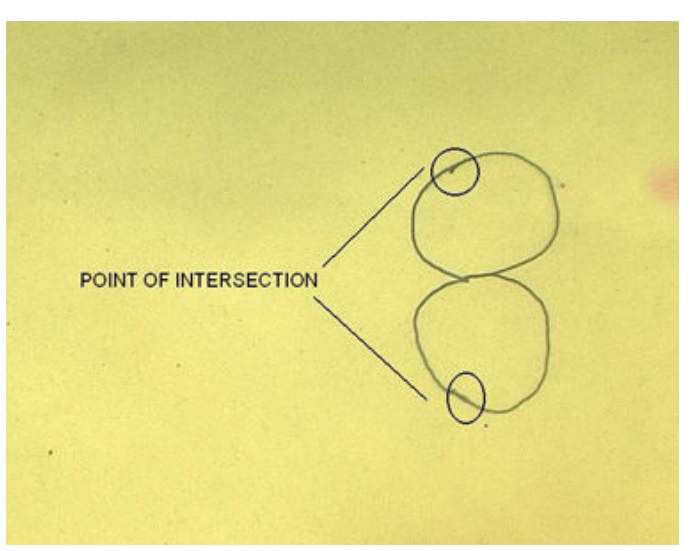

Figure 7: Image showing point of intersection of two different ball pen ink exhibit-5 and exhibit- 6 , under VSC-5000 light $=100 \%$, long pass $=$ visible.

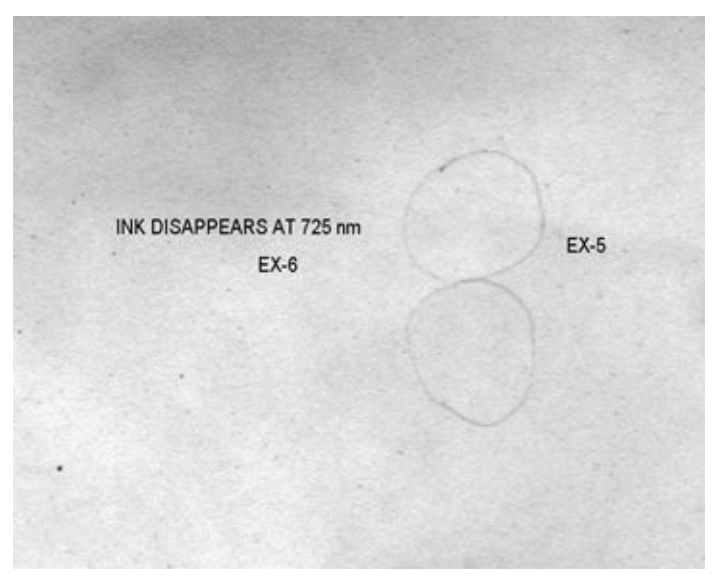

Figure 8: Ink of exhibit 6 shows absorption at $725 \mathrm{~nm}$ however ink of exhibit 5 does not show any absorption up to $778 \mathrm{~nm}$. 
Citation: Khairkar SR, Gaikawad SV, Kokare RN, Daundkar BB (2016) Forensic Discrimination Potential of Video Spectral Comparator and Micro Spectrophotometer in Analyzing Question Document and Fraud Cases in India. J Forensic Res 7: 329. doi:10.4172/2157-7145.1000329

Page 4 of 4

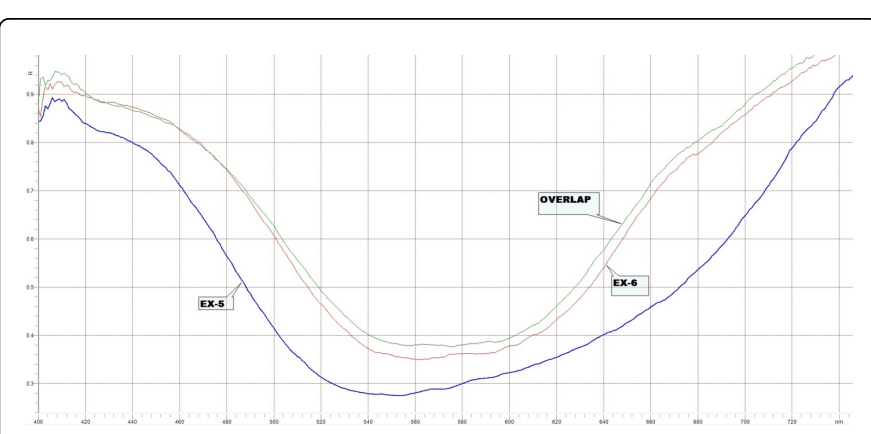

Figure 9: Graph of reflectance vs. wavelength in which overlap (point of intersection) portion graph of digit 8 is similar to graph of exhibit 6.

\section{Conclusion}

Non-destructive physical methods such as reflected infrared, infrared luminescence and micro spectrophotometry remain important valuable tools for the document examiners as they do not alter the visual morphology of the document. This is very important especially in the case of documents that have court or financial value. In forensic discrimination cases generally initial writing is overwrite or determination of interpolation, substitution, addition, over writings, decipherment of the mechanically and chemically erased writings. MSP graph and VSC images under different wavelength, we concluded that the pattern of color scan spectra of intersection's point matches with second pen ink which used overwrite it and we can conform which type of ink was used to overwritten and it has lot of important in cheating cases under court of law. MSP and VSC can be new horizon in nondestructive question documents analysis. Our results and our final conclusion suggested that MSP technique is a complementary and very useful non-destructive technique to the common non-destructive methods. Although other is a well established technique for the comparison of inks, it can be successfully replaced by the MSP.

\section{References}

1. Smalldon KW (1969) The comparison of ink in dyestuffs using minimal quantities of writing. J Forensic Sci Soc 9: 151-152.

2. Laing DK, Isaacs MDJ (1983) The comparison of nanogram quantities of ink using visible microspectrometry. J Forensic Sci Soc 23: 147-154.

3. Rodger C, Dent G, Watkinson J, Smith E (2000) Surface-enhanced resonance raman scattering and near-infrared Fourier transform raman scattering as in situ probes of ink jet dyes printed on paper. Appl Spectrosc 54: 1567-1576.

4. Claybourn M, Ansell M (2000) Using raman spectroscopy to solve crime: inks, questioned documents and fraud. Sci Justice 40: 261-271.

5. Tappolet JA (1983) The high performance thin layer chromatography (HPTLC). Its application to the examination of writing inks. Forensic Sci Int 22: 99-109.

6. Totty RN, Ordidge MR, Onion LJ (1985) A comparison of the use of visible microspectrometry and high performance thin layer chromatography for the discrimination of aqueous inks used in porous tip and roller ball pens. Forens Sci Int 28: 137-144.

7. Kher AA, Green EV, Mulholland MI (2001) Evaluation of principal component analysis with high-performance chromatography and photodiode array detection for the forensic differentiation of ballpoint pen inks. J Forensic Sci 46: 878-883.

8. Olson LA (1986) Color comparison in questioned document examination using micro spectrophotometry. J Forensic Sci 31: 1330-1340.

9. Roux C, Novotny M, Evans I, Lennard C (1999) A study to investigate the evidential value of blue and black ballpoint pen inks in Australia. Forensic Sci Int 101: 167-176.

10. Thanasoulias NC, Parisis NA, Evmiridis NP (2003) Multivariate chemometrics for the forensic discrimination of blue ballpoint pen inks based on their vis spectra. Forensic Sci Int 138: 75-84. 